\title{
Human-Computer Interaction through Sociological Lens
}

\author{
Liliia V. Zemnukhova
}

\begin{abstract}
Interaction is the central category of Human-Computer Interaction (HCI) research area. The main purpose of HCI is to make interaction with computer systems usable. Usability of interface forms the basis of the HCI logic. However, there are some conceptual problems with interaction within the discipline. Sociological perspective provides a shift of attention and an alternative view on problematization and conceptualization. Therefore, the article bears epistemological character. In this article, human-computer interaction is treated as an object of sociology after the material turn, and in particular Science and Technology Studies (STS). Though this approach does not any explanations, it fundamentally changes frames of references. As a result, human-computer interaction becomes a new possible object of sociology, though sociology itself is not quite ready to take it.
\end{abstract}

Index Terms-Human-computer interaction, science and technology studies, sociology, material turn.

\section{INTRODUCTION}

Human-computer interaction (HCI) is not only an interdisciplinary field. It is also research and practice area. Most of researchers and practitioners of the HCI tend to be non-academic actors, but they unavoidably face theoretical problems in their researches. The main reason is that there is a great pragmatic bias and orientation on practical results. Nevertheless, every particular research or practice is still embedded in a specific theory, whether authors are aware of it or not.

The field of HCI researches is being successfully carried out since it was formed into separate discipline. However, there was a considerable amount of changes within the field caused by interruptions and expansions of with utterly diverse sciences and theories. As a result, these theories were practiced, and it was the only way of implementation. On the next stage, practice was determining theories, technologies, and application evaluation. At that moment it became clear, that competent practice requires intellectual schooling, not limited by practical experience.

\section{SocIOLOGY TO HCI}

\section{A. The Context}

HCI practitioners and researchers are influenced by different trends and tendencies of the "big science". In these

\footnotetext{
Manuscript received April 4, 2013; revised May 15, 2013. This work was supported in part by the Russian Presidential Academy of National Economy and Public Relations, Moscow, Russia.

L. V. Zemnukhova is with the Russian Presidential Academy of National Economy and Public Adinistration (RANEPA), Moscow, Russia (e-mail: 1.zemnukhova@gmail.com).
}

conditions, conceptual frame of the field is not clear and pure. It is possible to find fundamental problems concerning the notions.

During few last decades, HCI field itself is losing its independence, at least in a theoretical sense. Key notions are put under the question. The role of sociology here is to produce the grounded area, where the problems of user-computer, human-non-human interaction might be revised. Science and technology studies (STS), for example, in this view are able to provide fruitful basis. Nevertheless, not only STS (and theories of practice in the broader sense) build foundation for further researches on a specific theoretical basis. It is necessary to find sociological resources, tools and optics, which need to be and could be more elaborated with the help of HCI.

\section{B. The Problem with HCI}

The HCI field is an advancing discipline. It deals with manifold issues and practical tasks. Though activity of researchers and practitioners is rather directed at solving particular problems, they generally use achievements in science and technology for own purposes. The HCI field puts in a claim for independent area of knowledge. This means that it is not just an institutionalized discipline, but also scientific enterprise. In this case, it is required for HCI to have its own conceptual apparatus. Despite the fact that HCI do has own set of notions and definitions, the inner problems remain. This is observable mostly during the period of changing of a dominating paradigm. As a result, the key notions of HCI, such as interaction, interface, usability, and others, change their meanings, and their status within the field.

Interface and usability, for example, could serve as genuinely HCI notions. The interaction is arguable in this case. The point is that HCI has no single definition for each of its basic notions, and it depends on several factors, that is: 1) what paradigm dominates, 2) which sciences and disciplines come to the foreground, and 3) what are vital needs and particular problems associated with processes that are more global. Understanding of interaction and choosing research paradigm is determined by some kind of 'fashion' on interface and usability criteria (for instance, ubiquitous or wearable computers which have diverse requirements). All these things are too interconnected to divide them. Nevertheless, the basic concept is still interaction, which additionally attracts great attention from sociology.

The hypothesis is that sociology had enough means and resources to define human-computer interaction. Therefore, it was supposed that this definition would have deeper theoretical roots and would cover the most aspects in order to make more or less constant understanding and defining of the HCI key concepts out of the context. 


\section{HCI: QUESTIONS AND CONCERNS}

\section{A. What is HCI?}

What is HCI as separate field? Researches and practice of the HCI field are in order to make technologies available and usable. Technical aspects of this activity become insufficient for successful dealing with problems of human-computer interaction, especially, from the human's position. This, in turn, leads to the necessity of searching for the new ways of human-computer interaction analysis, because old methods and procedures did not cover all the aspects of this type of interaction. The focus is shifted to human aspect and its activity towards computer. To achieve their main purpose support of successful interaction - researchers make innovative design decisions, develop new technologies, and interaction models.

However, interaction as a central category of the HCI is not the only notion or issue of this research field. Usability becomes the main purpose of the most HCI researches for the sake of producing this interaction. Usability determines interaction first. At the same time, there is no way to understand and conceptualize usability without the notion of interface, which is also significant in the HCI theory. The range of rules, methods and tools for human-computer interaction makes an interface by the use of which this inter-, or mutual, action is getting possible [1]. Successful and unproblematic interaction depends on how careful and clear interface is designed. In other words, the usability requirement is necessarily abided in the interface design in a process as well as in the result. Finally, the purpose of the HCI practice is to support safe and productive user's experience. HCI researches combine in this way conceptions about usability and resources for its achievement. These are the main ideas underlying the HCI.

As a result, HCI became a successful technological and even scientific enterprise [2]. Software engineering and human factors of computer systems were integrated efficiently with the help of concepts and methods from diverse sciences. Yet HCI researches seem to be fragmentary. This means that the field is expanding, and its grounds are changing constantly. There is an extreme mixture of theories, methods, systems, and ranges of application. Owing to its "interdisciplinarity", HCI has managed to enrich and enlarge its conceptual apparatus as well as methods and techniques. In this way, HCI came through and was affected by different scientific turns and interruptions, such as a cognitive one. Consequently, practitioners started searching for new ways of solving internal matters. Whereas researchers and developers of conceptual schemes are in great demand, only few of them provide fundamentally new decisions. The point is that it is not enough to stay in the same theoretical borders for HCI researchers and practitioners. They realize their difficulties, because technology, science, and society continue to change, and especially in interrelations. Finally, some key questions are in the air.

\section{B. Key Questions and Sociology}

HCI seems to deal with understanding of human-computer interaction. However, it is hard to find clear and evident answers following questions: what is interaction, how human-computer interaction "works", what roles user and computer play, who define them as participants of interaction process, how this process flows, and others. HCI uses large amount of techniques to solve these problems and apply them in the 'real life'. However, it still needs new concepts, frameworks, and theories in order to broaden the field. Expansion of HCI allows examining of human-computer interaction on the new levels.

Sociology is able to give such an opportunity. It might to provide resources, language and logic for reinterpretation and redefinition of the notion of human-computer interaction. In so doing, sociology does not solve problems of the HCI field, but mainly reveals them. The aim is not to get into the HCI field and make moves from the inside, but to make an area for interaction between sociology and HCI, or at least, to find areas of contact between these two fields of study. This is to enrich sociology as well.

Human-computer interaction is (or is about to become?) an actual and stable object in sociology. However, it is better not to ignore the HCI field. The matter, which is left, is the question of how this interconnection is possible. Turn to sociology is treated in this article as the path towards new approaches and ways of thinking. It will result in an entirely new conceptual apparatus for broadening of heuristic potential of HCI researches.

Human-computer interaction may be considered in the framework of sociology with the precondition to treat it as social interaction. In few words, the treatment of the category of interaction makes sense within two relative periods of sociology. The central figures of the first (classical) period are Georg Simmel and Max Weber whose fundamental ideas were laid in the basis and determined development of the future theories. The second one is interactionist theories starting from the authors of "Introduction to the Science of Sociology" Robert Park and Ernst Burgess from the Chicago school, moving to the representatives of symbolic interactionism (George Herbert Mead, Herbert Blumer), ethnomethodology (Harold Garfinkel), and frame-analysis (Erving Goffman). Unfortunately, there is no opportunity to consider all these theories and conceptions. The idea is to indicate which of them could be useful for human-computer interaction defining indeed.

\section{Social Theory as a Resource}

Most theories do not grant full-fledged apparatus for the research of human-computer interaction. If human-computer interaction may be considered as social, it must be justified. Most approaches regarded humans as participants of interaction. Some schools continue to develop independently, exceeding the bounds of "classic" understanding of interaction and methods of its research. In so doing, Goffman's frame-analysis [3] and Garfinkel's ethnomethodology [4] allowed to redefine roles of objects in interaction and became a part (or predecessors) of the material turn in sociology. The material turn is characterized by the following tendency: material objects are treated as actively participating in interaction and determining it. Though neither Goffman, nor Garfinkel emphasize the subject matter of the material as the major one, they provided a basis for this turn. Whether this sociological trend considers human-computer interaction as its own (or possible) subject it represents a fruitful and significant step in this direction. 


\section{HuMAN AND COMPUTER: IS INTERACTION POSSIBLE?}

\section{A. The Notion of Interaction}

The revision of the theories and concepts becomes more specific with human-computer interaction. The object under consideration is dynamical and blurred. Though interaction still seems to be a sociological notion, there could not be found a mere way of definition applying to the human-computer interaction yet. So far, the notion of interaction was a part of great sociological constructions, connected with diverse levels, societal as well as individual. Moreover, traditional views do not even provide any possible means and tools for the treatment of human-computer interaction.

STS gave such an opportunity; however, it is not a pure sociology in a sense. The thing, which is left, is constructing of the optics, lens for the research. HCI represents a continuous and renovating complex of human-computer interaction researches. At that moment, when interaction itself (but not some of its aspects) becomes the subject under consideration, great number of problems emerges. Interaction paradigms in HCI are constantly changing. Every stage of human-computer interaction development has its own specific features. Consequently, it is almost impossible to construct (or choose) any universal explanation or definition.

Sociological grounding for the reinterpretation of interaction takes role. Why should we solve HCI-problems and define human-computer interaction, if it is not yet clear whether it has any sense? Sociology is able to provide tools and logic for HCI, but what if it is not universal and useful? Even if these two fields of knowledge - sociology and HCI are mostly different, there is no sufficient reason to discrete any of them. Instead of trying to help each other or making new field on the crossing, it might be more useful to discover some kind of trance-connection, which could be fruitful with the help of epistemological level of science, whereas demarcation and ontology are defined as follows.

Whether human-computer interaction is considered from the 'social' position or not, sociology has some difficulties in defining it or explaining how it could be possible. However, there are no doubts if this type of interaction exists, at least, in contemporary life. (For theorizing it, we could use grounded theory method for constructing own theoretical positions and statements.) Not to take communication with the help of computer into account, it is needed to say that mostly relations with computer could be defined as existing and unquestionable. "I constantly talk with my computer, who answers back... Yet, this behavior is considered by sociologists as a scandalous breach of natural barriers" [5].

\section{B. Sociology as a Diversity of Optics}

HCI could exist further without the help of sociology. However, social context research becomes one of the last tendencies in the HCI field. Partly, such researches are conducted with the help of ethnomethodology. Ethnomethodological position presents another view on the social interaction and objects in the interaction process. Garfinkel gives new understanding of the role of material objects in the social interaction. Following the underlying principles of ethnomethodology, we can say that there is no universal and definite meaning/sense of the object but only the concrete, here-and-now using of it. The notion of as-of-which object "indicates several aspects of the objectiveness - the situation which the object is included in, its connection with other objects within this situation, the functional place in the space and time, which he accepts" [6]. According to Garfinkel, normative structure does not work or give any normative situations. It is remarkable how social order is put into effect but not how it is 'in the real life'. In this sense, it is not a matter of principle which objects (or subjects?) are interacting. What is more important is that the interaction is observable and, thus, describable. Actions have indexical properties; it means that contextual location determines and elaborates their sense. One of the relevant examples is a workplace studies treating contexts and activity [7]. Such an analysis of human-computer interaction was first conducted by Lucy Suchman, though her research turns towards computer-medium communication [8].

Ethnomethodological approach served as a method for the HCI that allowed discovering and describing some new fundamental aspects [9]. This approach reduced certain problems and provided new methods of research (such as observation of the workplace, for example), and gave an opportunity to consider not only technical aspects, but also the human's role. However, HCI is still confused by other questions and still has difficulties with the notion of interaction and fundamentals in general. Etnomethodology is not capable of providing them. As a result, this methodology is not able to solve conceptual problem. The HCI field will turn to sociology by itself; moreover, there is no need to 'recover' human-computer interaction research and take them up on the level of science in the full sense of the word. Tendencies are observable and interpretable on the different levels - practical (in the case with HCI-practitioners) or theoretical (machines are making "ambiguous the difference between the natural and the artificial" by Haraway, for instance [10]).

HCI solves particular problems even if it appeals to 'high theory'. This matter should be considered as the basis of their activity. In addition, this condition is essential when we deal with HCI as a research of human-computer interaction. While attempting to rethink logic, we inevitably face the problems of definitions and redefinitions of major categories and notions, which are necessarily definable and have to be clear. Any attempt to focus on creating its own methodology or ways of the human-computer interaction research on the new basis and levels condemned to failure. It happens because whatever constructivist move is made it requires fundamental revision of simple theoretical statements and the whole theory consequently. If computer is an inanimate object, there is nothing to analyze from sociological point of view, because such interaction (human with computer) is not social in a strict sense.

When we talk about interaction in sociology, we usually imply social interaction. However, owing to Latour and his Actor-Network Theory (ANT), purely 'social' relations were transformed into different kind of 'socio-technical' ones where humans, as well as computers, and as well as nature and texts take part [5]. As we could see, this logic (the ANT logic) provides an excellent description and does not try to explain the phenomenon. Peculiarity of meaning of the phenomenon is in computer itself. It is not simple non-human actor, but the inter-actor, which is ascribed with functions of 
a real human and respective attitude towards it. Depending on how a human (user) acts towards a computer (system), the latter appears to be humanized or not. This is the user who constructs an image of computer as an image of human; and this is the designer who makes it possible. Such social constructivism leads to the problem of interaction itself. This path either leads to the deadlock of circular definitions, or does not gives anything from the sociological point of view, because it is not supported by any theory in general. Why do not we consider the problem of the human-computer interaction in the terms of 'pure forms' then (in Simmel's sense)?

\section{Formal Sociology and HCI}

It should be clear that Simmel's formal sociology is a complex enterprise. To use it for sociological theorizing of human-computer interaction means to accept the key statements and always revise results. Taking that society is a psychological interaction among humans; we should note that computers are perceived as such psychological beings. This assumption is realized owing to the Haraway's cyborg concept, where humans and machines mixed and act as similar things. Society, according to Simmel, is constantly regenerated by interaction [11]. In this case, interaction with a computer plays specific role too. Users, as well as professionals, make these technologies work and function. The more computers become a part of human life, the more society, communities, and individuals are interconnected. (Additionally, a computer is often considered as a mediator, and this point was consciously evaded.) Thus, the claim here is to treat the human-computer interaction not as merely social interaction, but as a pure form, that maintains the existence of society. Not those who interacts, but the very process of interaction is of the greatest importance. The step toward similar understanding of human-computer interaction is being made. This assumption is also supported by the requirement of paying no attention on the content of such forms.

What does this understanding give to our main problem? Sociology examines forms of interaction as such, and thus gives not only description of the process (which can easily be given by the HCI researches) but also provides a starting point for possible HCI theory. Instead of changing interaction paradigms and construct new particular theories, it would be better to evaluate interaction as a form, which plays the first role in contemporary society. This form has to be researched and examined. Even if a computer never becomes a human, we must not underestimate the role of "every ware" [12] in everyday life and as the supporter of social life.

Different paradigms from the HCI are evidence of how dynamically human-computer interaction changes in the content. Moreover, these examples show that sociology is lacking appropriate vocabulary and methods for research of the human-computer interaction phenomenon.

\section{CONCLUSION}

It turned out that sociology despite its rich and elaborated vocabulary, fundamental theoretical background, hermetical language, and constructible ways of description, has no appropriate tools and means to explain human-computer interaction as social one. Moreover, it faces serious difficulties when the matter is not purely clear. In other words, interaction in HCI and interaction in sociology are two different things, which cannot be confronted, and a fortiori replace each other. The problem, more precisely, is that sociology could revisit HCI categories (as they are similar), but does not provide basis for the definition. However, there is a way out of the situation. The matter is that sociology itself is under the interdisciplinary influence, thus interested in broadening of own borders. The search for the HCI definitions allows discovering new ways of interpretation, definition, and even new language forming. By the end of such collaboration, the result is achieved. It happened partly owing to STS and its means, tools, and language.

The notion of interaction in the HCI field meets difficulties because of the human-computer development specific features. Constant switching of interaction paradigms leads to unstable model of interaction within the HCI. On the one hand, they work out general understanding of human-computer interaction, i. e. any contact with computer. On the other hand, any shifting of them shows their inability to represent the specific forms of human and computer communication. Decision, which is proposed from sociological point of view, is also not the only probable one. However, any attempt to find 'the ultimate truth', be it human-computer interaction or any other concept or idea, fails at the very beginning. Scientific truth is not an evident thing, and there is no final possible explanation of the phenomenon. Whatever result is found, it is expected to lose its relevance some time later.

In the case of human-computer interaction as an object and the HCI field, sociology just approves dynamic character of interaction. HCI is not able to solve its problems, but it does not have to. HCI (similar to ANT) describes a reality in its own terms and does not explain anything. The problems, which are solved there, are mostly practical. Fundamental theory was not fully formed by the HCI theorists. Researchers are still face different theoretical problems and change subjects of interest.

Sociology provides explanations. Owing to its hermetical explanations, the HCI phenomena are definable as well. However, sociology has to revisit its own tools and methods before explaining human-computer interaction. In so doing, classical theories and postclassical conceptions are unable to consider human-computer interaction as pure sociological object. Moreover, none of them gives any role to a computer.

STS made sociology turn its focus to the other perspectives, where material objects are the part of interaction (not merely mediators, according to Goffman), the inter-actors. Nevertheless, "the descriptive turn has emasculated the normative dimension of science studies and in the process has limited the field's potential for radical critique and revision of our knowledge enterprises" [13]. This is the reason for revisiting of theories and frames of references. HCI is indeed too dynamical to be framed into any stable theoretical borders.

\section{ACKNOWLEDGMENT}

I thank my scientific advisor Alexandr F. Filippov for the detailed review on my Master thesis, which became the beginning of the research. I also want to thank my closest 
colleagues Pavel M. Stepantsov and Victor S. Vachshtayn, who made valuable comments on the first versions of the article.

\section{REFERENCES}

[1] J. Raskin, The Humane Interface: New Directions for Designing Interactive Systems, Boston: Addison-Wesley, 2000.

[2] J. M. V. Carroll, "Toward a multidisciplinary science of human-computer interaction," in HCI Models, Theories, and Frameworks: Toward a Multidisciplinary Science, J. Carroll, Ed., USA: Morgan Kaufmann Publishers, 2003, Introduction, pp. 1-10.

[3] E. Goffman, Interaction Ritual: Essays on Face-to-Face Behavior, New York: Pantheon Books, 1982.

[4] H. Garfinkel, Ethnomethodology's Program: Working Out Durkheim's Aphorism, Lanham, Maryland, USA: Rowman and Littlefield Publishers, 2002.

[5] B. Latour "Where are the missing masses? Sociology of a few mundane artefacts," in Shaping Technology, Building Society: Studies in Sociotechnical Change, W. Bijker and J. Law, eds. Cambridge, Mass, MIT Press, 2002, pp. 225-258.

[6] V. S. Vakhshtain (2004). 'Vozvrashenie material'nogo. 'Prostranstva'. 'seti'. 'potoki' v aktorno-setevoy teorii. Sotsiologicheskoe obozrenie. [Online]. 3(4). Available: http://sociologica.hse.ru/s11/11sta1.pdf

[7] L. Suchman, Located Accountabilities in Technology Production. Centre for Science Studies. Lancaster University. Lancaster LA1 4YN. UK. [Online]. Available: http://www.comp.lancs.ac.uk/sociology/papers/Suchman-Located-Ac countabilities.pdf

[8] L. Suchman, Human/Machine Reconsidered, Department of Sociology, Lancaster University, 2000.
[9] G. Button and W. Sharrock, "Ethnomethodology and HCI," paper presented at the CHI'95 Research Symposium, Denver, CO, USA, 1995.

[10] D. J. Haraway, Simians, Cyborgs, and Women: The Reinvention of Nature, London: Routledge. 1991.

[11] G. Simmel, "The Sociology of Georg Simmel," K. H. Wolff, ed., New York, Free Press, 1964.

[12] A. Greenfield, Everyware: The Dawning Age of Ubiquitous Computing, Berkeley, CA: New Riders Press, 2006.

[13] S. Fuller, "Social epistemology and the research agenda of social studies," in Science as Practice and Culture, A. Pickering, ed. Chicago, University of Chicago Press, 1992, pp. 390-428.

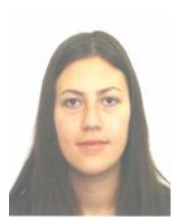

Liliia V. Zemnukhova was born in the city of Alma-Ata, USSR, on the $4^{\text {th }}$ of May 1987. After higher education was got at the Department of Sociology of St. Petersburg State University, $\mathrm{PhD}$ research was started at the Sociological Institute of the Russian Academy of Sciences, 2009. The degree of MA in Sociology affiliated with the University of Manchester was earned in 2011. The major field of study is sociology of technology, human-computer interaction, IT-community.

Since 2007, she worked as an Assistant, and then as a Junior Researcher at Sociological Institute of the Russian Academy of Sciences. After earning MA degree, she started to teach Bachelor students and to work as Senior Research Fellow at the Russian Presidential Academy of National Economy and Public Administration (RANEPA) in Moscow, Russia.

Ms. Zemnukhova received award from the Russian Academy of Sciences being included in the list of "Top $100 \mathrm{PhD}$ students of the RAS", in 2010. Ms. Zemnukhova also won scholarship for education on Master Program, 2010-2011. 